Review

\title{
Pathophysiology of Ischemic Heart Disease with Special Reference to the Degree of Organic Stenosis of the Coronary Artery
}

\author{
Motoomi Nakamura \\ Graduate School of Health and Nutrition Sciences, Nakamura-Gakuen College, Fukuoka, Japan.
}

In this "OHSHIMA-SHO" Award-lecture, I will address four questions related to the pathophysiology of ischemic heart disease, with special reference to the degree of organic coronary stenosis.

\section{The first question concerns sudden cardiac death.}

Is the rate of sudden cardiac death in patients with angina pectoris related to the degree of organic coronary stenosis?

Although the annual death rate from ischemic heart disease appears to be declining in the United states, sudden cardiac death remains an important problem, particularly in japan, where the rate is on the increase. We reviewed the clinical characteristics and the long term prognosis of 158 consecutive Japanese patients with variant angina and compared the data with those in major western studies (1). The Japanese patients were characterized by the low prevalence of significant coronary stenosis and previous myocardial infarction, and as expected, the overall prognosis of variant angina was significantly better in the Japanese patients than in the non-Japanese populations.

On angiography coronary artery stenosis and left venticular dysfunction are the major prognostic determinants in ischemic heart disease. However, it remains unclear whether sudden cardiac death also depends on the degree of organic coronary stenosis.

In collaboration with 8 different Institutions in Japan, we followed a total of 349 patients with angiographicallyproven vasospastic angina for a period of 3.4 years (2). While the risk of sudden death and malignant arrhythmia did not depend on the presence of significant organic

\footnotetext{
This article was presented at the 24th annual meeting of the Japan Atheroscierosis Society in Osaka.

Address for correspondence: Motooml Nakamura, Graduate School of Health and Nutrition Sciences, NakamuraGakuen College, 5-7-1, BEFU, Johnan-ku, Fukuoka, 814-01, Japan.
}

stenosis, the presence of a significant fixed stenosis did increase the risk of myocardial infarction, as shown in Table 1. Cardiac death and myocardial infarction occurred in $2 \%$ and $5 \%$ during the 3.4 years of follow-up, rates were considerably lower than those found in studies in Western countries. This study differs from most previous studies in that the severity of organic coronary stenosis was assessed from findings of coronary angiography, before and after the administration of nitroglycerin. Thus, the role of fixed organic stenosis, as a risk factor for sudden death and myocardial infarction was examined only in those who underwent this procedure. Five patients died suddenly and one of the 5 had significant organic stenosis. Similarly, malignant arrhythmia, such as ventricular tachycardia and fibrillation and advanced A-V block were evident in 48 patinents and 38 of these 48 did not have any significant stenosis. Thus, sudden death as well as malignant arrhythmia occur in the absence of any significant stenosis in patients with vasospastic angina, particularly multivessel coronary spasm (3-5).

Davies and Thomas (6) noted in autopsy studies that the pathologic process in sudden cardiac ischemic death is a rapidly evolving thrombus formation associated with plaque fissuring, findings similar to the pathology of acute transmural myocardial infarction. In their study, a large thrombus occupying more than $76 \%$ of the lumen was present in 18 of 74 patients. They wrote "the idea that patients who die suddenly from ischemic disease fall into two groups those with occlusive thrombus and those without is an oversimplification". "Virtually all patients who die suddenly of ischemic heart disease have active progressing arterial lesions that are predominantly thrombotic". However, in 30 of the total 74 autopsied patients in their study, the size of the thrombus occupying the lumen was less than $50 \%$, and it would be difficult to develop acute myocardial ischemia unless coronary spasm was involved. Coronary spasm in present day medicine can be identified only by coronary angiography. 
Table 1. Coronary anfiographic findings in patients with and without complications.

\begin{tabular}{|c|c|c|c|c|}
\hline & $\begin{array}{l}\text { Fixed } \\
>75 \%\end{array}$ & $\begin{array}{c}\text { stenosis } \\
<75 \%\end{array}$ & Normal & Total \\
\hline No Complication & 79 & 112 & 48 & 239 \\
\hline Sudden death & 1 & 4 & 0 & 5 \\
\hline \multicolumn{5}{|l|}{ Myocardial Infarction } \\
\hline nonfatal & 9 & 3 & 2 & 14 \\
\hline Fatal & 2 & 0 & 0 & 2 \\
\hline \multicolumn{5}{|l|}{ Arrhythmia } \\
\hline \multicolumn{5}{|l|}{ VT and/or VF } \\
\hline 2-and/or-3-degree AVB & 3 & 14 & 5 & 22 \\
\hline $\mathrm{VT} / \mathrm{Vf}+\mathrm{AVB}$ & 0 & 0 & 3 & 3 \\
\hline Total & 101 & 145 & 62 & 308 \\
\hline
\end{tabular}

(From (ref. 2) with permission of the American Heart Association. Inc.)

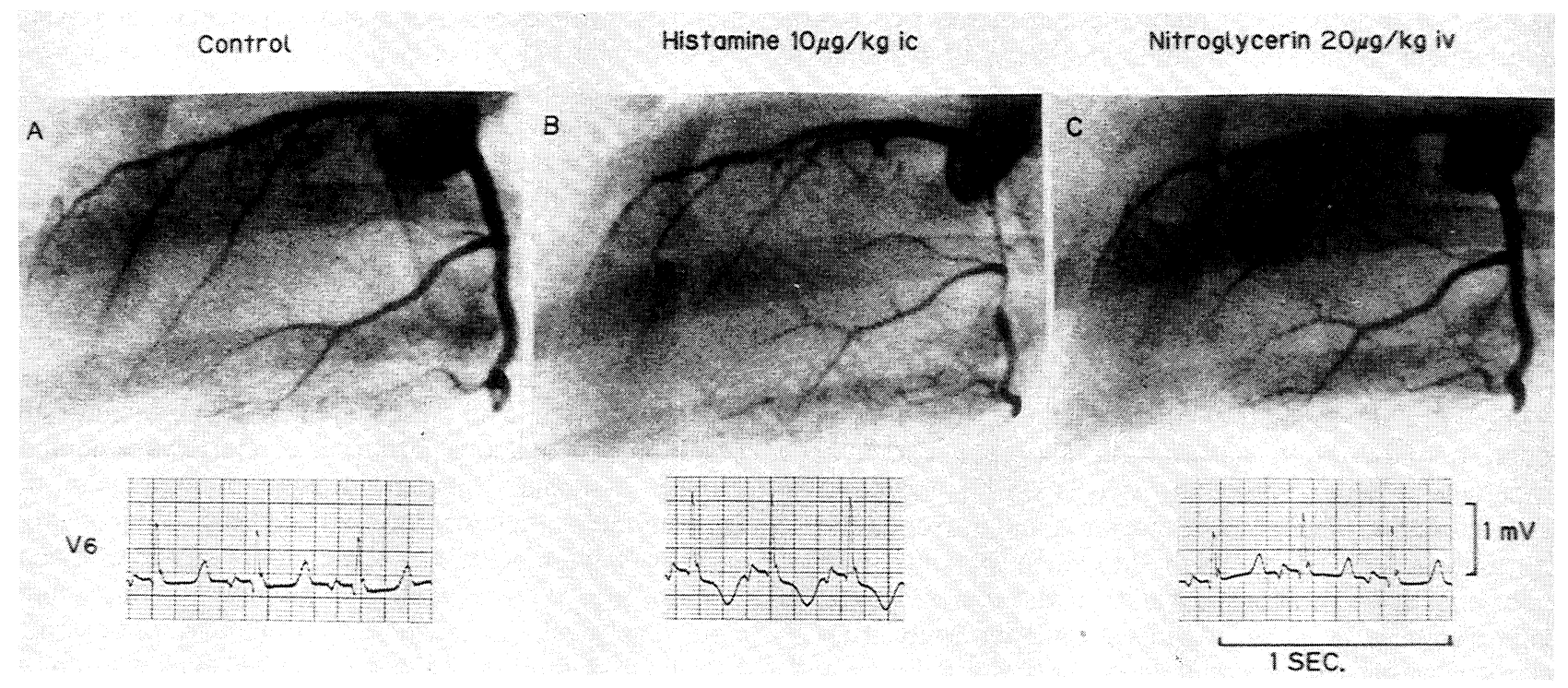

Fig. 1. Coronary angiograms and electrocardiograms obtained at contol (A) and after histamine (B) and nitroglycerin administration (C) from a representative pig with spontaneous coronary atherosclerosis. Tubular type of vasoconstriction is evident along the major trunk of the left circumflex coronary artery after intracoronary administration of $10 \mathrm{ug} / \mathrm{Kg}$ histamine. The angiogram obtained after nitroglycerin shows no organic lesion in either the left anterior decending or circumflex arteries. Electrocardiogram recorded at V6 shows ST depression after histamine (B). (From (ref. 18) used with permission of the American Heart Assoc. Inc).

In our animal model of coronary spasm in atherosclerotic miniature swine, coronary thrombosis was not evident even in animals in which spasm was repeatedly provoked (7). However extrapolating the results of animal studies to the human must be done with caution because of the complexity of the responses of human arterial wall to various stimuli.

Differing from the findings of Davies and Thomas (6), several pathological studies including work done in Japan found the incidence of coronary thrombi to be less than $10 \%$ in sudden death (8-11), there-by suggesting that the most likely cause of sudden cardiac death is arrhythmia rather than acute myocardial infarction due to coronary thrombosis. Clinical studies of resuscitated survivors of sudden death revealed that acute myocardial infarction had occurred only in a minority of these patients(12). Studies of sudden cardiac death must include nationwide epidemiological approaches, large scale of autopsyrelated data and experiments using atherosclerotic animals. In Japan, there is a great paucity of those studies. 


\section{The second question concerns the relation between} fixed atherosclerotic narrowing and the dynamic obstruction such as coronary vasospasm.

Traditionally, fixed stenosis and dynamic stenosis are considered to be unrelated. In the United States, few cardiologists seem to think that coronary spasm is an important cause of ischemic heart disease. In a previous publication (13), I discussed the history of the concept of coronary spasm, evidence for its role in various types of angina, and the role of spasm in the development of acute myocardial infarction and sudden death. Singh (14) reported the episodic nature of progression in coronary stenosis, as shown by repeated coronary angiographic studies done on cases of coronary artery disease. He emphasized that coronary atherosclerosis does not progress gradually in a linear fashion. It is well known that in patients with variant angina, acute myocardial infarction often occursd in the area supplied by the spastic coronary artery. However, the relation between transient coronary spasm and progression or occlusion of the coronary artery has not been vigorously studied. Virmani et al. (15) pointed out that most patients with cocaine-related infarct do not have typical plaque fissuring. Kolodgie et al. (16) suggested that an increase in adventitia mast cells associated with atherosclerosis could potentiate thrombus and vasospasm in young patients with cocaine-associated death. They pointed out that atherosclerotic lesions in cocaine-users with coronary thrombosis did not demonstrate atheroma-rupture or intramural hemorrhage, thereby suggesting that the pathophysiology of acute myocardial infarction differs from that observed in noncocaine-users. Attention must be directed to pathological changes that lead to a stepwise progression of the clinical episodes, plaque fissuring, the resulting in thrombus and its organization. The cause of plaque fissuring or other factors leading to thrombus formation also need to be investigated. It is generally accepted that the normal artery rarely become thrombotic, because there is no in vivo coagulation in the absence of vascular damage.
CONTROL

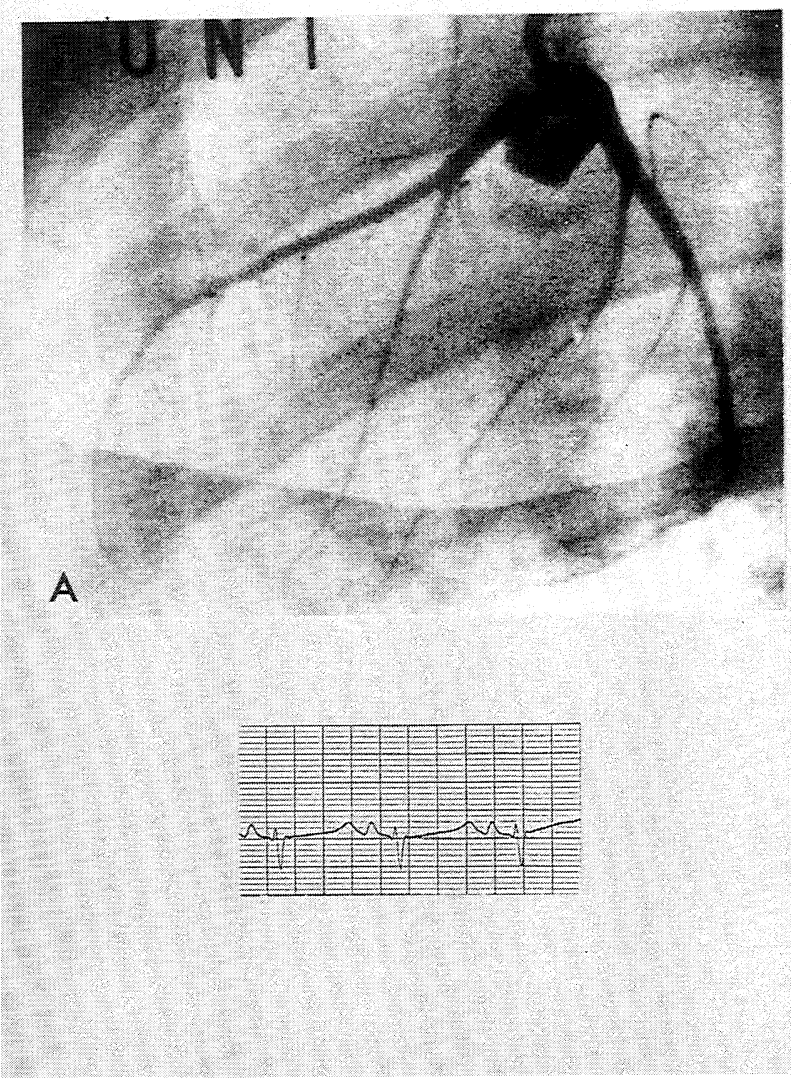

SEROTONIN $10 \mu \mathrm{g} / \mathrm{kg}$ i.c.

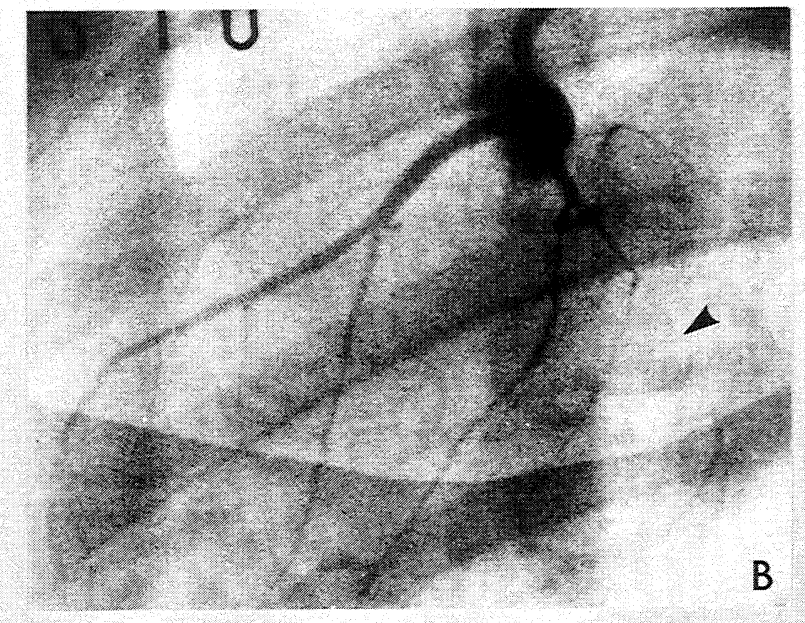

Fig. 2. Left coronary angiograms (left anterior oblique projection) of control (A) and repetitive provocations $(B)$ of serotonin-induced coronary spasm. Subtotal stenosis was noted along the left circumflex coronary artery. Arrow points to the severe spastic site. During coronary spasm, ECG-ST elevation was recorded. (From (ref. 7) with permission of the American Heart Assoc. Inc.) 
To determine whether coronary spasm is linked to vascular injury which progresses to atherosclerosis or thrombus formation, in 1983 we developed an animal model of coronary spasm in atherosclerotic miniature swine (17). We found that the presence of atherosclerosis is essential to provoke spasm of the coronary artery by the intracoronary administration of autacoids, histamine and/or serotonin, in both spontaneous and/or experimentally-induced coronary atherosclerosis as shown in Fig. 1(18). These atherosclerotic miniature swine had a normal coronary angiogram prior to the induction of coronary spasm. Histological studies always showed the early atherosclerotic lesions at the spastic sites not only at sites denuded by a balloon but also at the spontaneously occurring atherosclerotic sites. We found that $X$-ray irradiation is the most fruitful and

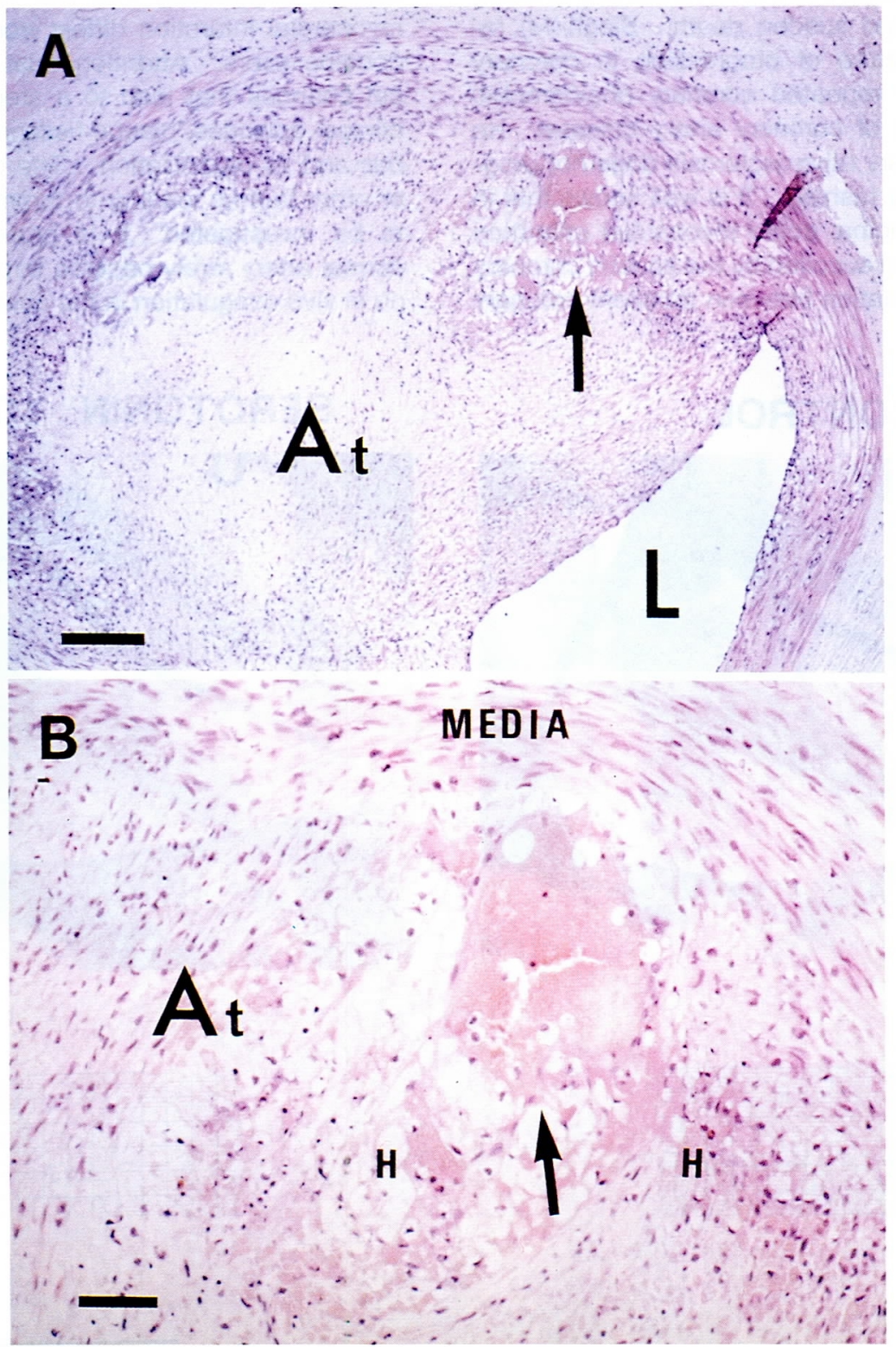

Fig. 3. Microscopic features of the vessel with induced hemorrhage. A : Low-power magnification view. Bar represents $200 \mathrm{um}$. At, atheroma; L, Lumen. Arrow indicates the site of intramural hemorrage, which is further magnified in B.B: High-power magnification view. Bar represents 80 um. Red blood cells (allow) are preserved in their original shape, and there is no evidence of histiocytic reaction or hemosiderin deposition. Arrow points to red blood cells. (From (ref. 7) used with permission of the American Heart Assoc. Inc). 
Table 2. Percent area stenosis along the spastic vessel (morphological determination).

\begin{tabular}{lccc}
\hline & $\begin{array}{c}\text { Proximal } \\
(\%)\end{array}$ & $\begin{array}{c}\text { Spastic Site } \\
(\%)\end{array}$ & $\begin{array}{c}\text { Distal } \\
(\%)\end{array}$ \\
\hline Group A & $15 \pm 7$ & $23 \pm 5$ & $16 \pm 6$ \\
Group B & $13 \pm 4$ & $56 \pm 7$ & $16 \pm 3$ \\
\hline
\end{tabular}

Date are presented in Mean \pm SEM. Samples of the proximal and distal sites were taken 5 to $10 \mathrm{~mm}$ apart from the most severe spastic site. Calculation of the area stenosis is described in the text. (From (ref.7) with permission of the Americal Heart Association Inc.)

rapid method of producing coronary lesions which are susceptible to spasm, in terms of high reproducibility. In these X-ray irradiated swine fed a high cholesterol diet, severe coronary spasm was repeatedly provoked by serotonin, as shown in Fig. 2 (7). In 4 pigs, coronary spasm was provoked only once (Group A in Table 2) and in 6 (Group B in Table 2) spasm was repeated 5 times at 5 min intervals. As shown in Fig. 3 and Table 2, intramural hemorrhage was present at the spastic site in all 6 pigs in group $B$ and the average luminal narrowing at the spastic site was significantly greater than that at sites proximal or distal to the spastic site. In group $A$, there was no intramural hemorrhage. These findings in swine indicate that severe spasm alters vascular integrity, including the endothelial lining and produces intramural hemorrhage from newly developed capillaries in the atheromatous lesions. These results are consistent with the hypothesis that coronary spasm can have an important role in the progression of atherosclerosis. However, we have not succeeded in provoking plaque fissuring or thrombus formation in this swine model. We are now looking to see which type of atherosclerotic lesions are likely to rupture, and the mechanisms involved in development of atheroma-rupture and thrombus formation in atherosclerotic animals. Perhaps blood coagulation and/or sudden elevations of blood pressure or severe spasm in addition to moderately advanced atherosclerosis are required to rupture an atheroma.

\section{Pathophysiology of acute myocardial infarction and percent stenosis of the infarct-related vessels.}

Coronary thrombosis as a cause or result of acute myocardial infarction was a subject of discussion for many years $(19,20)$. Recent achievements in thrombolytic therapy and coronary arteriography during the early stage of myocardial infarction support the notion that total coronary obstruction results from a rapidly evolving coronary thrombus at the site of plaque-fissuring or that atheroma-rupture is the main cause of most transmural acute myocardial infarction. However, the exact nature and mechanisms of acute onset of the thrombic occlusion is less certain.

Dewood et al. (21) reported that the rate of angiographic, complete occlusion of the coronary artery related to acute myocardial infarction decreased gradually from $87 \%$ within 4 hours to $68 \%$ during $6-12$ hours and was $65 \% 24$ hours after onset; this was confirmed by many cardiologists. It seems that the acutely occluded thrombi in the infarct-related coronary artery lysed as a result of its own thrombolytic activity of the coronary artery, hence the gradual decrease in the degree of coronary stenosis after an acute onset. During thrombolytic therapy, coronary angiography will show the remaining eccentric stenosis with a narrowed neck, overhanging edges and scalloped borders, findings which suggest the presence of rupture of the athroma. From these clinical and pathological findings, the historical theory (19) claiming that coronary thrombosis is not a cause but a result of acute myocardial necrosis, can hardly be supported. There is abundant information on coronary artery abnormalities immediately after acute myocardial infarction. Yet, little is known of the degree of coronary stenosis in patients in whom the coronary artery completely occluded and acute myocardial infarction ensues. In 1988, Ambrose et al. (22) and Little et al. (23) did retrospective studies on the progression of coronary stenosis between two cardiac catheterizations in patients who developed acute myocardial infarction. Their studies demonstrated that acute coronary thrombotic occlusion with myocardial infarction frequently developed from previously insignificant or nonsevere lesions. In other words, it is often difficult to predict the site of a subsequent thrombotic occlusion from analysis of the first coronary angiography. More recently, Webster and his group did prospective studies on preexisting coronary lesions in patients in whom acute myocardial infarction subsequently occurred (24). They also found that $85 \%$ of the infarct-related lesions were initially an insignificant (0-75\%) stenosis. Total occlusion developed from the significant more severe lesion but often did not progress to acute myocardial infarction probably because the slow progression of coronary stenosis is associated with a well developed collateral circulation. Therefore, acute coronary occlusive thrombi resulting in acute myocardial infarction often develop suddenly and in areas of mild or moderate lesions detected angiographically. On the contrary, Falk described pathological findings of completely occlusive thrombi in association with a histological stenosis exceeding $75 \%$ (25). There are few reported experiments in which thrombus was produced on the arterial surface in animals with an atherosclerosis. We have repeated the experiments reported by Constantinides and Chakravarti (26), using Russel's viper venom to elevate blood coagulability, in addition to the intravenous administration of serotonin or angiotensin in rabbits fed a $1 \%$ cholesterol diet intermittently for 8 months. We found that thrombus was produced in the aorta but rarely in the coronary arteries 
although scattered acute myocardial necrosis was evident (27). Thrombogensis is not only an immediate cause of acute myocardial infarction, it is also an important determinant of atherosclerotic progression $(28,29)$. There are cases where a higher concentration of thrombotic factors is present in patients with ischemic heart disease. The Northwick Park Heart Study (30) noted a strong relationship between the level of coagulation factor VII activity and the later incidence of ischemic heart disease. The high level of factor VII activity is known to lead to higher levels of thrombin production and causes an increased incidence of thrombus formation (31). There are also studies of an association between high levels of plasma fibrinogen and the incidence of ischemic heart disease (32). It was also reported that the activity of factor VII was higher in women on oral contraceptives who experienced ischemic heart disease than in non-users (33). Experimentally, the increase in dietary fat intake led to an increased level of factor VII activity (34). Wilcox et al noted that normal endothelial cells in direct contact with blood do not synthesize or store tissue factor and that the deposition and synthesis of tissue factor protein in the necrotic core of the plaque may contribute to the thrombogenecity of human atherosclerotic arteries (35). Blood coagulation is intiated when plasma factor VIla binds to its essential factor, and proteolytically activates coagulation factor $X$ and $I X(36)$. The atheromatous lesion contains marcrophages with tissue factor and proteolytic enzymes (37).

\section{The fourth question concerns small vessel disease present in the coronary arterial tree.}

Using angiographic techniques, the large conduit coronary artery can be visualized but abnormalities in the small vessels of coronary circulation are difficult to define. Small coronary arteries are most important in regulating myocardial perfusion. Recently, Marcus et al developed a new technique for studying the epicardial microcirculation in the normal beating heart of a dog, using stroboscopic illumination (38). However, the dog is resistant to hypercholesterolemia and coronary atherosclerosis and there are few animals models of small coronary arterial disease. New technology and a new animal model of small coronary artery disease are needed for such studies. We recently noted severely narrowed small coronary arteries in rabbits fed a 1\% cholesterol diet for 2 months cycle, separated by 2 months interval on normal diet for total of 8-9 months (39). The incidence of small coronary arterial occlusive lesion seems to be much higher in intermittently hyperlipidemic rabbits than those in the WATANABE heritable hyperlipidemic rabbits, although the degree of aortic atherosclerosis was comparable (39). It would be ideal to conduct experimental trials in an animal model of coronary arterial lesions that closely simulate the condition in humans with regard to coronary circulation abnormalities. Both molecular pathology and studies on whole animal pathology needed to be done in parallel.

Acknowledgements : I greatly acknowledge the supprot and contribution of Drs. Y. Kikuchi, A. Takeshita, $H$. Kanaide, H. Tomoike, Y. Nose, T. Fukuyama, O. Nakagaki, Y. Koiwaya, S. Koyanagi, K. Sunagawa, Y. Kawachi, H. Ohtubo, Y. Maruoka, T. Matsuguchi, Y. Shimokawa, A. Suyama, S. Nabeyama, H. Araki, K. Ohzono, Y. Urabe, H. Yamamoto, T. Inoue, K. Egashira, Y. Yamamoto, J. Sadoshima, Y. Hayashi, A. Yamada, M. Mohri, H. Tsutsui, K. Nagasawa, Y. Nagata, S. Sato, H. Nishijima, K. Kuga, H. Tagawa, W. Mituoka, S. Egashira, T. Irie, (from Research Institute of Angiocardiology, Kyushu University Faculty of Medicine and S. Abe (from Nakamura Gakuen-College). It has been my good fortune to work with them since the 1970s, toward our common goal of elucidating the pathophysiology of ischemic heart disease, particularly coronary vasospasm. I am grateful for support from the Ministry of Education, Science and Culture, Ministry of Health and Welfare, Uehara-Memorial Foundation, and the Salt Science Research Foundation (9131). I am also grateful to M. Ohara for critical comments.

\section{References}

(1) Shimokawa H, Nagasawa K, Irie T, Egashira S, Egashira K, Sagara T, Kikuchi $Y$, and Nakamura M: Clinical characteristics and long-term prognosis of patients with variant angina. A comparative study between western and Japanese populations. Intern $\mathrm{J}$ Cardiol, 18: 331349, 1988

(2) Nakamura M, Takeshita A, and Nose Y: Clinical characteristics associated with myocardial infarction, arrhythmia, and sudden death in patients with vasospastic angina. Circ, 75 : 1110-1116, 1987

(3) Koyanagi S, Takeshita A, and Nakamura $M$ : Clinical characteristics of sudden death in patients with vasospastic angina. Jpn Circ J, 53: 1541-1545, 1989

(4) Igarashi $Y$, Tamura $Y$, Tanabe $Y$, Yamazaki $Y$, Yamaguchi T, Fujita T, Yamazoe M, Izumi T, and Shibata A: Relationship of multivessel coronary spasm in patients with variant angina to disease activity, age and extent of coronary atherosclerosis. Coronary artery Dis, 2 : 985991, 1991

(5) Yasue H, Takizawa A, Nagano M, Nishida S, Horie M, Kubota J, Omote S, Takaoka K, and Okumura K : Longterm prognosis for patients with variant angina and influencing factors. Circ, 78: 1-9, 1988

(6) Davies MJ, and Thomas A: Thrombosis and acute coronary artery lesions in sudden cardiac ischemic death. New Engl J Med, 310: 1137-1140, 1984

(7) Nagasawa $K$, Tomoike $H$, Hayashi $H$, Yamada A, Yamamoto $\mathrm{T}$, and Nakamura $\mathrm{M}$ : Intramural hemorrhage and endothelial changes in atherosclerotic coronary artery after repetitive episodes of spasm in X-ray irradiated hypercholesterolemic pigs. Circ Res, $65: 272-282$, 1989

(8) Tokutome S: Nature of sudden death based on autopsy (in Japanese). Therap Res, $7:$ 974-976, 1987 
(9) Kragel AH, Reddy SG, Wittes JT, and Roberts WC: Morphometric analysis of the composition of atherosclerotic plaques in the four major epicardial coronary arteries in acute myocardial infarction and in sudden coronary death. Circ, $80: 1747-1756,1989$

(10) Friedman M, Manwaring $\mathrm{JH}$, Rosenman $\mathrm{RH}$, Donlon $\mathrm{G}$, Ortega $P$, and Gurbe $S M$ : Instantaneous and sudden deaths : Clinical and Pathological differentiation in coronary artery disease. JAMA, 255: 1319-1328, 1973

(11) Spain DM, and Bradess VA : Sudden death from coronary heart disease: survival time, frequency of thrombi, and cigarette smoking. Chest, 58: 107-110, 1970

(12) Liberthson RR, Nagel EL, Hirschman JC, Nussenfeld SR, Blackbourne BD, and Davis $\mathrm{JH}$ : Pathophysiologic observations in prehospital ventricular fibrillation and sudden cardiac death. Circ, 49: 790-798, 1974

(13) Nakamura $M$ : Pathophysiology of ischemic heart disease with special reference to coronary artery spasm in "Coronary circulation in physiological and pathophysiological states" Ed. by Nakamura M. and Vanhoute P.M. Springer-Verlag, Tokyo, 59-88, 1991

(14) Singh RN : Progression of coronary atherosclerosis; Clues to pathogenesis from serial coronary angiography. Br Heart J, 52 : 451-461, 1984

(15) Virmani R, Kolodgie FD, Robinowitz M, Goodin J, Fields F, Smialek JE, and Forces A : Cocaine associated coronary thrombosis coexists with atherosclerosis. Circ, 80 suppl II: II-647, 1989

(16) Kolodgie FD, Virmani R, Cornhill JF, Herderick EE, and Smialek JE: Increase in atherosclerosis and adventitial mast cells in cocaine abusers: an alternative mechanism of cocaine-associated coronary vasospasm and thrombosis. J Am Coll Cardiol, 17 : 1553-1560, 1991

(17) Shimokawa $H$, Tomoike $H$, Nabeyama S, Yamamoto $H$, Araki $\mathrm{H}$, Nakamura $\mathrm{M}$, Ishii $\mathrm{Y}$, and Tanaka $\mathrm{K}$ : Coronary artery spasm induced in atherosclerotic miniature swine. Science, 221: 560-562, 1983

(18) Egashira K, Tomoike H, Yamamoto Y, Yamada A, Hayashi $Y$, and Nakamura $M$ : Histamine-induced spasm in regions of intimal thickening in miniature pigs: roles of serum cholesterol and spontaneous or induced intimal thickening. Circ, $74: 826-837,1986$

(19) Baroldi G, Radice F, Schmid G, and Leone A : Morphology of acute myocardial infarction in relation to coronary thrombosis. Am Heart J, $87: 65-75,1974$

(20) Chandler AB, Chapman I, Roberts WC, Schwarz CJ, Sinapius D, Spain DM, Sherry S, Ness PM, and Simon TL: Coronary thrombosis in myocardial infarction in relation to coronary thrombosis. Am J, Cardiol, 34 : 823-833, 1974

(21) DeWood MA, Spores J, and Notsuke R: Prevalence of total coronary occlusion during the early hours of transmural myocardial infarction. N Engl J Med, 303: 897 902, 1980

(22) Ambrose JA, Tannenbaum MA, Alexopoulos D, Hjemdahl-Monsen CE, Leavy J, Weiss M, Borrico S, Gorlin R, and Fuster V: Angiographic progression of coronary artery disease and the development of myocardial infarction. J Am Coll Cardiol, 12 : 56-62, 1988
(23) Little WC, Constantinescu M, Applequte RJ, Kutcher MA, Burrows MT, Kahl FK, and Santamore WP : Can coronary angiography predict the site of a subsequent myocardial infarction in patients with mild-to-moderate coronary artery disease? Circ, 76: 1157-1166, 1988

(24) Webster MWI, Chesebro JH, Smith HC, Frey RL, Holmes DR, Reeder GS, Bresnaham DR, Nishimura RA, Clementsa IP, Barsley WT, Grill DE, Bailey KR, and Fuster V: Myocardial infarction and coronary artery occlusion: a prospective 5-year angiographic study. J Am Coll Cardiol, 15 suppl A : 218A, 1990

(25) Falk $E$ : Plaque rupture with severe pre-existing stenosis precipitating coronary thrombosis. Br Heart J, $50: 127$ 134, 1983

(26) Constantinides $P$, and Chakravarti RN : Rabbit arterial thrombosis production by systemic procedures. Arch Pathol, 72 : 79-90, 1961

(27) Nakamura $\mathrm{M}$, and $\mathrm{Abe} \mathrm{H}$ : (unpublished observation)

(28) Smith EB and Staples EM: Haemostatic factors in human aortic intima. Lancet, 1: 1171-1174, 1981

(29) Smith EB : Fibrinogen, fibrin and fibrin degradation products in relation to atherosclerosis. Clinics in Haematology, 15 : 355-370, 1986

(30) Meade TW, Mellows S, Brozovic M, Miller GJ, Chakrabarti RR, North WRS, Haines AP, Stirling Y, Imeson JD, and Thompson SD: Haemostatic function and ischemic heart disease : Principal results of the Northwick Park Heart study. Lancet, 2 : 533-537, 1986

(31) Meade TW: Hypercoagulability and ischemic heart diesase. Blood Reviews, 1: 2-8, 1987

(32) Wilhelmsen L, Svadsudd K, Korsan-Bengtsen K, Larsson $B$, Welin $L$, and Tibblin $G$ : Fibrinogen as a risk factor for stroke and myocardial infarction. $\mathrm{N}$ Engl J Med, 311: 501-505, 1984

(33) Poller L, and Thompson JM: Clotting factors during oral contraception. Further report. Br Med J, 2 : 23-25, 1966

(34) Miller GJ, Martin JC, Webster J, Wilkes H, Miller NE, Wilkinson $\mathrm{WH}$, and Meade TW: Association between dietary fat intake and plasma factor VII coagulant acti vity-a predictor of cadiovascular mortality. Athelosclerosis, 60 : 269-277, 1986

(35) Wilcox JN, Smith KM, Schwartz SM, and Gordon D: Localization of tissue factor in normal vessel wall and in the atherosclerotic plaque. Proc Natl Acad Sci USA, 86: 2839-2843, 1989

(36) Broze GJ, Girard TJ, and Novotny WF : Regulation of coagulation by a multivalent Kunitz-type inhibitor. Biochemistry, 29 : 7539-7546, 1990

(37) Nathan CF : Secretory products of macrophages, J Clin Invest, 79: 319-326, 1987

(38) Marcus ML, Chilian WM, Kanatsuka H, Dellsperger KC, Eastham CL, and Lamping KG: Understanding the corony circulation through studies at the microvascular level. Circ, $82: 1-7,1990$

(39) Nakamura M, and Abe S : Small coronary artery sclerosis of the intermittent hypercholesterolemic rabbit differs from that of the hereditary hypercholesterolemic rabbit. Circ 86 : suppl I, I-371 (1992). 